\section{Editorial}

Check for updates

\title{
Sex Differences in Cardiac Remodeling in Athletes: Men on the Left, Women on the Right?
}

\author{
Chi Young Shim (D, MD, PhD \\ Division of Cardiology, Severance Cardiovascular Hospital, Yonsei University College of Medicine, Seoul, \\ Korea
}

- See the article "Gender Difference of Cardiac Remodeling in University Athletes: Results from 2015 Gwangju Summer Universiade” in volume 51 on page 426.

Received: Jan 20, 2021

Accepted: Jan 29, 2021

Correspondence to

Chi Young Shim, MD, PhD

Division of Cardiology, Severance

Cardiovascular Hospital, Yonsei University

College of Medicine, 50-1, Yonsei-ro,

Seodaemun-gu, Seoul 03722, Korea.

E-mail: cysprs@yuhs.ac

\section{Copyright $(\subset) 2021$. The Korean Society of Cardiology \\ This is an Open Access article distributed under the terms of the Creative Commons Attribution Non-Commercial License (https:// creativecommons.org/licenses/by-nc/4.0) which permits unrestricted noncommercial use, distribution, and reproduction in any medium, provided the original work is properly cited.}

ORCID iDs

Chi Young Shim (iD)

https://orcid.org/0000-0002-6136-0136

\section{Funding}

The author received no financial support for the research, authorship, and/or publication of this article.

Conflict of Interest

The author has no financial conflicts of interest.

Data Sharing Statement

Data sharing is not applicable to this article as no new data were created or analyzed.
Long-lasting athletic training leads to alteration in cardiac structure and function, which allows the generation of a large stroke volume to the body with effective energy consumption. ${ }^{11}$ In such physiologic adaptation, it is known that the degree of cardiac remodeling varies according to race, type of sport, and training time. ${ }^{2}$ Moreover, after some degree of physiologic adaptation, it becomes an arrhythmia prone substrate that can progress to pathologic conditions. ${ }^{1)}$ Another important factor for exercise-induced cardiac remodeling may be the sex of the athlete; limited studies have been reported on sex differences since most of the studies on cardiac remodeling have been focused on male athletes. ${ }^{34)}$

In this issue of Korean Circulation Journal, Yoon et al..$^{5}$ present valuable data regarding exerciseinduced cardiac remodeling in 1,185 highly trained university athletes. This study highlights sex differences in cardiac remodeling in athletes, and also shows what is in common regardless of sex. The main sex difference that the authors emphasize is that male athletes have more remodeling of the left chambers, and female athletes have more remodeling of the right ventricle (RV). ${ }^{5}$ The common points are that exercise-induced cardiac remodeling in any cardiac chamber was common regardless of sex, and remodeling of the left ventricle (LV), left atrium (LA), or RV does not overlap in many cases. ${ }^{5)}$ Such results cannot be explained clearly through the well-known pathophysiology of athletes' hearts but such data need to be analyzed with interest. Previous studies published by the same research group have shown that female athletes had less LV volume and mass, higher LV ejection fraction, higher absolute value for LV global longitudinal strain, and less LA enlargement than male athletes. ${ }^{2(6) 7)}$ The present study adds information about $\mathrm{RV}$ remodeling to the analysis of previous studies and focuses more on sex differences.

Despite interesting findings that showed $\mathrm{RV}$ remodeling happens more often in female athletes, we need to think carefully before accepting these new results. First, absolute values for RV size were larger in male than female athletes, however, the body surface area (BSA)-indexed RV dimensions were greater in female athletes. ${ }^{5)}$ Likewise, when we look at the LA and LV sizes as a dimension, the absolute values are also larger in male than female athletes, but the BSA-indexed LA and LV dimensions are greater in female athletes. The reason why RV remodeling was more common in female athletes was the RV dimensions were calculated and then indexed with BSA. Moreover, if the RV volume is calculated by 
The contents of the report are the author's own views and do not necessarily reflect the views of the Korean Circulation Journal. three-dimensional echocardiography or cardiac magnetic resonance imaging and corrected by BSA, the key findings of this study are likely to reverse. Second, the racial distribution of athletes participating in this study was $40.9 \%$ Caucasian, $23.7 \%$ Asian, and $11.9 \%$ African as described in a previous report. ${ }^{2}$ As this study group reported that $\mathrm{LV}$ remodeling was frequent in individuals of African descent, there is a possibility that ethnic differences as well as sex differences exist in $\mathrm{RV}$ remodeling.

The results of this study give and motivate a future perspective on athlete hearts. Recently, interest in $\mathrm{RV}$ remodeling in athletes and differentiation of physiologic $\mathrm{RV}$ remodeling from arrhythmogenic cardiomyopathy has increased because intense exercise might induce RV inflammation and fibrosis. ${ }^{18-10)}$ Also, it seems to be important to investigate pulmonary artery remodeling and exercise-induced pulmonary hypertension in athletes since an abnormal increase in pulmonary artery systolic pressure can lead to RV dilatation and dysfunction. Therefore, in the future, RV volumetric assessment, myocardial tissue characterization, evaluation of the pulmonary artery, and RV-pulmonary artery coupling by multimodality imaging may clarify sex differences in RV remodeling in athletes and the clinical implications associated with this remodeling.

\section{REFERENCES}

1. Sharma S, Merghani A, Mont L. Exercise and the heart: the good, the bad, and the ugly. Eur Heart J 2015;36:1445-53. PUBMED | CROSSREF

2. Cho JY, Kim KH, Rink L, et al. University athletes and changes in cardiac geometry: insight from the 2015 Gwangju Summer Universiade. Eur Heart J Cardiovasc Imaging 2019;20:407-16. PUBMED | CROSSREF

3. Finocchiaro G, Sharma S. Do endurance sports affect female hearts differently to male hearts? Future Cardiol 2016;12:105-8. PUBMED | CROSSREF

4. Whyte GP, George K, Nevill A, Shave R, Sharma S, McKenna WJ. Left ventricular morphology and function in female athletes: a meta-analysis. Int J Sports Med 2004;25:380-3. PUBMED | CROSSREF

5. Yoon HJ, Kim KH, Hornsby K, et al. Gender difference of cardiac remodeling in University Athletes: results from 2015 Gwangju Summer Universiade. Korean Circ J 2021;51:426-38. CROSSREF

6. Park JH, Oh JK, Kim KH, et al. Left ventricular longitudinal strain and strain rate values according to sex and classifications of sports in the young university athletes who participated in the 2015 Gwangju Summer Universiade. JACC Cardiovasc Imaging 2018;11:1719-21. PUBMED | CROSSREF

7. Park JH, Kim KH, Rink L, et al. Left atrial enlargement and its association with left atrial strain in university athletes participated in 2015 Gwangju Summer Universiade. Eur Heart J Cardiovasc Imaging 2020;21:865-72. PUBMED | CROSSREF

8. D'Ascenzi F, Solari M, Corrado D, Zorzi A, Mondillo S. Diagnostic differentiation between arrhythmogenic cardiomyopathy and athlete's heart by using imaging. JACC Cardiovasc Imaging 2018;11:1327-39. PUBMED | CROSSREF

9. Rao Z, Wang S, Bunner WP, Chang Y, Shi R. Exercise induced right ventricular fibrosis is associated with myocardial damage and inflammation. Korean Circ J 2018;48:1014-24. PUBMED | CROSSREF

10. Park Y, Kim EJ. Prolonged intensive exercise: when the right ventricle goes wrong. Korean Circ J 2018;48:1025-7.

PUBMED | CROSSREF 